\title{
Avaliação da influência do glicerol em matriz cerâmica
}

\section{Evaluation of the influence of glycerol in ceramic matrix}

\author{
Adriane Lawisch Rodríguez ${ }^{1,2}$, Pâmela Andréa Mantey dos Santos ${ }^{2}$, \\ Adilson Becker $\mathrm{Jr}^{1}$, Ênio Leandro Machado ${ }^{2,3}$, Tiago Bender Wermuth ${ }^{4}$, \\ Sabrina Arcaro ${ }^{4}$, Diosnel Antonio Rodriguez Lopez ${ }^{1,2}$
}

\footnotetext{
${ }^{1}$ Departamento de Engenharia, Arquitetura e Ciências Agrárias, Universidade de Santa Cruz do Sul, Av. Independência 2293, CEP: 96815-900, Santa Cruz do Sul, Rio Grande do Sul, Brasil.

${ }^{2}$ Programa de Pós-Graduação em Tecnologia Ambiental, Universidade de Santa Cruz do Sul, Av. Independência 2293, CEP: 96815-900, Santa Cruz do Sul, Rio Grande do Sul, Brasil.

${ }^{3}$ Departamento de Química e Física, Universidade de Santa Cruz do Sul, Av. Independência 2293, CEP: 96815-900, Santa Cruz do Sul, Rio Grande do Sul, Brasil.

${ }^{4}$ Laboratório de Materiais Cerâmicos (LACER), Departamento de Materiais, Universidade Federal do Rio Grande do Sul, Av. Osvaldo Aranha, 99, CEP: 90035-190, Porto Alegre, Rio Grande do Sul, Brasil.

e-mail: adriane@unisc.br, pamelams20@gmail.com, adilsonbecker.jr@gmail.com, enio@unisc.br; tiago.haine@gmail.com, sabrinarcaro@yahoo.com.br, dlopez@unisc.br
}

\section{RESUMO}

O presente trabalho avalia os efeitos da adição de glicerol sobre a porosidade e resistência mecânica de um material cerâmico. As amostras foram compactadas por prensagem uniaxial e submetidas a temperaturas de queima de $950{ }^{\circ} \mathrm{C}$ e $1100{ }^{\circ} \mathrm{C}$, com taxa de aquecimento de $7{ }^{\circ} \mathrm{C} \mathrm{min}{ }^{-1}$. Foram realizados ensaios físicos e mecânicos para analisar porosidade aparente, absorção de água, retração linear e resistência mecânica a flexão. Os resultados mostram que a adição de $10 \%$ de glicerol à argila melhora principalmente suas propriedades mecânicas, podendo ser um aditivo promissor para gerar materiais cerâmicos estruturais com microestrutura mais resistente.

Palavras-chave: resíduo, glicerol, argila, cerâmica.

\section{ABSTRACT}

The present work evaluates the effects of the glycerol addition on the porosity and mechanical resistance of a ceramic material. Samples were compacted by uniaxial pressing and were submitted to different sintering temperatures, $950{ }^{\circ} \mathrm{C}$ and $1100^{\circ} \mathrm{C}$, with a heating rate of $7{ }^{\circ} \mathrm{C} \mathrm{min}{ }^{-1}$. Physical and mechanical analysis were performed to evaluate porosity, water absorption and linear retraction. The results show that the addition of $10 \%$ of glycerol into the clay mainly improves its mechanical properties, being able to be a promising additive to generate structural materials with more resistant microstructure.

Keywords: Waste, glycerol, clay, ceramics.

\section{INTRODUÇÃO}

Impulsionado pelo esgotamento das fontes de energias não renováveis, como o carvão e o petróleo, o biodiesel está cada vez mais em evidência quando se fala em sustentabilidade. A produção de biodiesel no Brasil chegou a aproximadamente 4 milhões de litros no ano de 2015 e a tendência é aumentar ainda mais nos próximos anos já que, desde novembro de 2014, a mistura obrigatória de biodiesel puro (B100) ao óleo diesel passou a ser de $7 \%$ em volume (exceto o óleo diesel para uso aquaviário) [1]. O biodiesel é obtido a partir da reação de transesterificação de um óleo com um álcool, podendo ser produzido a partir de diversos vegetais, como o girassol e a mamona, além de sebo bovino e, pode substituir o diesel de petróleo em motores que o 
utilizam, sem qualquer tipo de adaptação [2]. Porém, esta produção não apresenta apenas benefícios, pois gera subprodutos como o glicerol, que é um composto orgânico, também conhecido como glicerina ou propano-1,2,3-triol. O glicerol representa $10 \%$ do total da massa de biodiesel produzida [3-5]. A periculosidade do glicerol está associada a sua queima junto ao biodiesel, o que provoca a emissão de gases perigosos e a sua deposição em tanques de combustíveis, o que pode atrair outros contaminantes, como a água, diminuindo a vida útil dos motores [6]. O glicerol é um composto sem cor, sem odor, higroscópico e, por si só, não apresenta toxicidade, tanto para humanos quanto ao meio ambiente [5]. Esse subproduto não tem um mercado definido, por isso está passível de um descarte inadequado e por esta razão, torna-se importante investigar soluçães economicamente viáveis para a transformação do glicerol em produtos de maior valor agregado [1].

O desenvolvimento de estudos voltados à agregação de resíduos industriais e urbanos na indústria cerâmica representa uma alternativa capaz de contribuir para o uso de matérias-primas alternativas visando a diminuição dos custos finais dos setores industriais, além de preservar o meio ambiente $[7,8]$. Em busca de alternativas para a agregação de resíduos industriais em diferentes matrizes, uma das tendências é a sua incorporação na fabricação de cerâmica vermelha utilizada na construção civil (tijolos, blocos, telhas, tavelas, elementos vazados, tubos cerâmicos e argilas expandidas). Esta alternativa ganha destaque devido a seus métodos de produção e matérias-primas de baixo custo, elevado potencial de incorporação de resíduos, devido ao seu grande volume de produção, sem alteração nas propriedades do produto final $[7,9,10]$. Além disso, os produtos de cerâmica vermelha têm longa vida útil e boa capacidade de inertização de resíduos incorporados além de boa tolerância quanto à variabilidade das condições de processamento e variações de composição de suas matérias-primas [11]. Alguns exemplos de resíduos já agregados à matriz cerâmica são as de cinzas da casca de arroz, de lixívia de glicerina, de serragem, de granitos, de borra oleosa da produção de petróleo, resíduo oleoso da produção de azeite de oliva e resíduos gerados da produção do alumínio [12-17]. Sendo assim, a adição de resíduos industriais em matriz cerâmica pode ser uma alternativa para a redução dos impactos ambientais causados pela extração e beneficiamento da argila, como o consumo de energias não renováveis no processo produtivo. Ademais, o resíduo agregado pode substituir uma parcela significativa de argila pura $[12,13]$.

Neste contexto, a proposta deste trabalho é explorar o uso do glicerol adicionado à matriz cerâmica como forma de avaliação prévia e definição de parâmetros para observar a influência desta adição nas propriedades físicas e mecânicas da cerâmica, buscando alternativas para a valoração do resíduo da produção do biodiesel concomitante a diminuição da utilização da argila, o principal produto na produção de materiais cerâmicos.

\section{MATERIAIS E MÉTODOS}

Este trabalho foi realizado nas dependências do Laboratório de Valoração e Coprocessamento de Resíduos (LAVCOR) da Universidade de Santa Cruz do Sul (UNISC). A argila utilizada neste estudo foi gentilmente fornecida por uma indústria cerâmica da cidade de Candelária-RS. O glicerol comercial (Synth) utilizado não sofreu nenhum tipo de preparação. Inicialmente a argila foi seca a temperatura ambiente por $24 \mathrm{~h} \mathrm{e}$, em seguida, foi seca em estufa a $110^{\circ} \mathrm{C}$, por $24 \mathrm{~h}$. Posteriormente, foi submetida ao processo de moagem em um jarro de porcelana, contendo bolas de alumina, por aproximadamente $2,5 \mathrm{~h} \mathrm{em}$ moinho rápido de laboratório (Servitech CT-242) até o pó ficar 100\% passante em peneira 80 mesh.

A argila foi caracterizada por meio de análises de distribuição de tamanho de partículas, composição química, análise térmica diferencial e termogravimétrica e retração térmica linear.

A distribuição de tamanho de partículas foi determinada em um analisador de tamanho de partículas de varredura a laser (CILAS 1064L). A amostra foi preparada na forma de suspensão (amostra + água), com $10 \%$ em massa de sólidos e submetida à ultrassom para completa desaglomeração das partículas. Uma porção de suspensão foi, então, inserida no equipamento e realizada a leitura para determinação da distribuição de tamanho das partículas.

A composição química foi obtida por meio da técnica de fluorescência de Raios - X (FRX) (Shimadzu Sequential X-ray Fluorescence Spectrometer).

As análises térmicas diferencial (ATD) e termogravimétrica (TG) foram realizadas a $10{ }^{\circ} \mathrm{C} \mathrm{min}^{-1} \mathrm{em}$ atmosfera oxidante (TA instruments, SDT - 600). A curva de retração térmica linear foi obtida por meio de um dilatômetro ótico (Expert System solutions, Misura ODHT). As amostras utilizadas $(2 \times 3 \mathrm{~mm})$ foram aquecidas até $1300^{\circ} \mathrm{C}$ com uma taxa de aquecimento de $10^{\circ} \mathrm{C} \mathrm{min}^{-1}$, em atmosfera oxidante (ar).

Parte da argila foi misturada e homogeneizada com 10\% (massa) de glicerol e umidificadas com $2 \%$ de água. A argila pura e a mistura de argila com glicerol foram, em uma etapa posterior, compactadas uniaxialmente em matriz de aço por meio de uma prensa hidráulica (Nowak) a $40 \mathrm{MPa}$. 
As amostras obtidas, com $60 \times 20 \mathrm{~mm}$ foram secas $24 \mathrm{~h}$ em temperatura ambiente e submetidas a secagem em estufa a $110 \pm 10{ }^{\circ} \mathrm{C}$ por $48 \mathrm{~h}$. Posteriormente os compactos foram submetidos ao processo de queima em diferentes temperaturas, ou seja, $950{ }^{\circ} \mathrm{C}$ e $1100{ }^{\circ} \mathrm{C}$, ambas com taxa de aquecimento de $7^{\circ} \mathrm{C} \mathrm{min}^{-1}$. As amostras obtidas foram nomeadas de acordo com a Tabela 1.

Tabela 1: Nomenclatura das amostras.

\begin{tabular}{ccc}
\hline NOMENCLATURA & COMPOSIÇÃo & TEMPERATURA DE QUEIMA \\
100A950 & $100 \%$ Argila & $950{ }^{\circ} \mathrm{C}$ \\
10G950 & $90 \%$ Argila $+10 \%$ de Glicerol & $950{ }^{\circ} \mathrm{C}$ \\
100A1100 & $100 \%$ Argila & $1100{ }^{\circ} \mathrm{C}$ \\
$10 \mathrm{G} 1100$ & $90 \%$ Argila $+10 \%$ de Glicerol & $1100{ }^{\circ} \mathrm{C}$ \\
\hline
\end{tabular}

A retração linear dos compactos foi obtida para cada condição de tratamento térmico. As dimensões das amostras foram mensuradas antes e depois do processo de queima, com auxílio de um paquímetro digital (CD-6" CSX-B, Mitutoyo, EUA). A retração linear de queima $(R L Q)$ foi calculada por meio da Equação 1:

$$
R L Q=\left(\frac{L i-L_{f}}{L_{f}}\right) * 100
$$

onde $L_{i}$ é a medida do diâmetro da amostra não tratada termicamente (mm) e $L_{f}$ é a medida do diâmetro da amostra tratada termicamente $(\mathrm{mm})$.

A densidade aparente/geométrica $\left(\rho_{a}\right)$ dos compactos antes e após a queima foi calculada (Equação 2) a partir de medidas de massa por meio de uma balança (FA-2104-N, Bioprecisa, precisão de $\pm 0,001 \mathrm{~g}$ ) e de volume, por meio de um paquímetro digital (Digimess, precisão de $\pm 0,01 \mathrm{~mm}$ ).

$$
\rho_{a p}=\frac{m}{V}
$$

onde $m$ é a massa da amostra (g) e $V$ é o volume aparente da amostra $\left(\mathrm{cm}^{3}\right)$.

O teste de absorção de água $(A A)$ foi realizado por meio da imersão das amostras em água por $24 \mathrm{~h}$. Foram analisadas as massas antes da imersão, após a imersão e ainda saturado, a medida de massa da amostra imersa em água. Para esta análise, é utilizada a Equação 3:

$$
A A=\left(\frac{M_{u}-M_{s}}{M_{s}}\right) * 100
$$

onde $M_{u}$ é a massa da amostra saturada com água (g) e $M_{s}$ é a massa da amostra após secagem (g) .

Para o ensaio de porosidade aparente $(P A)$, são utilizadas as mesmas medidas de massa que foram realizadas na análise de absorção de água para as amostras, e a análise é feita com base na Equação 4:

$$
P A=\left(\frac{M_{u}-M_{s}}{M_{u}-M_{i}}\right) * 100
$$

onde $M_{u}$ é a massa da amostra saturada em água $(\mathrm{g}), M_{s}$ é a massa da amostra após secagem $(\mathrm{g})$ e $M_{i}$ é a massa da amostra imersa em água $(\mathrm{g})$.

Amostras foram seccionadas e a superfície de fratura foi observada por meio de análise em microscópio eletrônico de varredura (MEV, Evo-MA10, Carl Zeiss).

Para determinar a resistência mecânica das amostras após a queima, ensaios de flexão a quatro pontos foram realizados utilizando uma máquina universal de ensaios (DL10000, EMIC) com célula de carga de 50 $\mathrm{kN}$, velocidade de ensaio de $0,5 \mathrm{~mm} / \mathrm{min}$ no sentido de compressão e início de ensaio em $2 \mathrm{~N}$, seguindo a norma ASTM C - 133/97[14]. 


\section{RESULTADOS E DISCUSSÕES}

A Figura 1 mostra a distribuição do tamanho de partículas da argila. É possível observar que o teor de argilomineral ou "fração argila" é de aproximadamente $10 \%$ em massa. O teor de silte, partículas com tamanhos compreendidos entre 2 e $20 \mu \mathrm{m}$, é de aproximadamente $40 \%$ e, o teor de areia, que corresponde às partículas maiores que $20 \mu \mathrm{m}$ é de $50 \%$. O percentual correspondente a "fração argila" está intimamente relacionado à maior plasticidade da massa cerâmica em mistura com água, permitindo uma maior consistência plástica, o que possibilita, por exemplo, a utilização deste material para a obtenção de peças conformadas com menor quantidade de defeitos. Quanto maior o percentual da "fração argila", maior a plasticidade, isso porque os argilominerais se associam aos intervalos de tamanho de partículas. Na Figura 1 ainda é possível observar que $90 \%$ da distribuição de tamanhos de partículas da argila está abaixo de $86 \mu \mathrm{m}(\operatorname{Dv}(90)), 50 \%$ da

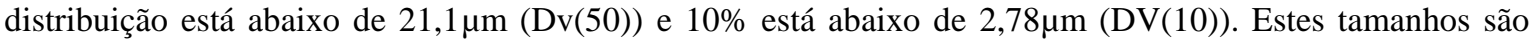
considerados adequados para a fabricação de cerâmica vermelha.

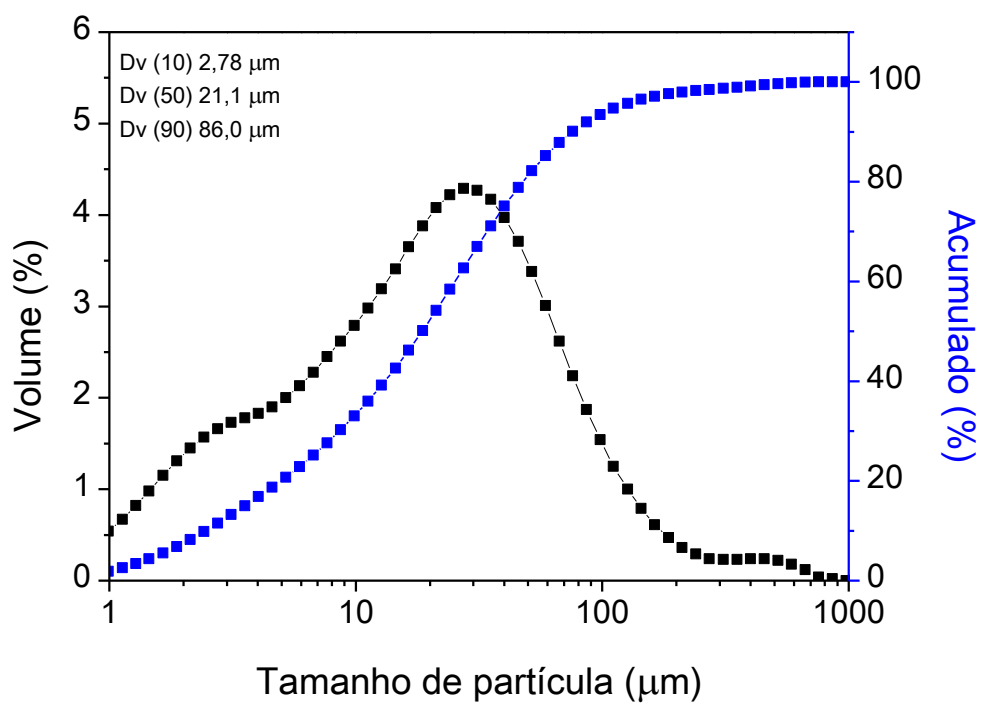

Figura 1: Distribuição granulométrica da argila.

A composição química das matérias primas obtida por fluorescência de raios -X (FRX), está descrita na Tabela 2. Pela análise da composição química da argila, é possível observar que a mesma é composta basicamente por sílica $\left(\mathrm{SiO}_{2}\right)$ e alumina $\left(\mathrm{Al}_{2} \mathrm{O}_{3}\right)$. A razão molar $\mathrm{SiO}_{2} / \mathrm{Al}_{2} \mathrm{O}_{3}$ é 4,17. Esse valor é relativamente elevado se comparado ao valor teórico $(2,00)$ calculado para a caulinita, o que sugere a presença de quartzo e outros silicatos. Os demais elementos presentes como $\mathrm{Fe}_{2} \mathrm{O}_{3}, \mathrm{~K}_{2} \mathrm{O}, \mathrm{MgO}, \mathrm{CaO}$ e $\mathrm{P}_{2} \mathrm{O}_{5}$ aparecem em teores quase que residuais. Todavia, os compostos alcalinos e alcalino-terrosos possuem efeito fundente, o que facilita a formação de fase líquida e a retração linear durante a queima [15-17]

Tabela 2: Composição química das matérias-primas.

\begin{tabular}{|c|c|c|c|c|c|c|c|c|c|c|c|c|c|c|}
\hline $\begin{array}{l}\text { ÓXIDOS } \\
\text { CONSTITUINTES }\end{array}$ & $\mathrm{SiO}_{2}$ & $\mathrm{Al}_{2} \mathrm{O}_{3}$ & $\mathrm{Fe}_{2} \mathrm{O}_{3}$ & $\mathrm{~K}_{2} \mathrm{O}$ & $\mathrm{CaO}$ & $\mathrm{TiO}_{2}$ & $\mathrm{MgO}$ & $\mathrm{MnO}$ & $\mathrm{ZrO}_{2}$ & $\mathrm{SrO}$ & $\mathrm{P}_{2} \mathrm{O}_{5}$ & $\mathrm{Rb}_{2} \mathrm{O}$ & $\mathrm{ZnO}$ & Perda ao Fogo \\
\hline
\end{tabular}

A argila utilizada nesse estudo pode ser considerada como uma típica cerâmica vermelha, pois apresenta concentração percentual de $\mathrm{SiO}_{2}, \mathrm{Fe}_{2} \mathrm{O}_{3}$ e $\mathrm{Al}_{2} \mathrm{O}_{3}$ nas faixas de concentração características de $(43,2$ a $77,6 \%),(1,36$ a 9,6\%) e (9,9 a 38\%), valores característicos de uma argila vermelha[18].

O melhor desempenho da argila utilizada está associado ao teor de sílica pois, confere resistência na fabricação de cerâmica vermelha, reduzindo a plasticidade e controlando a retração de queima.

Com a finalidade de avaliar o comportamento térmico e determinar as melhores condições de queima da argila com posterior adição do glicerol, foram realizadas análises térmicas. Pela análise de termogravimetria (TG) apresentada na Figura 2, observa-se que há uma perda de massa total de aproximadamente $11 \%$. A primeira etapa desta perda em massa corresponde a $5 \%$ e ocorre na faixa de temperatura de 30 a $100{ }^{\circ} \mathrm{C}$, e se 
refere a eliminação da umidade (água adsorvida) presente no material. A segunda etapa, corresponde a $6 \%$ de perda em massa na faixa de temperatura de 450 a $600^{\circ} \mathrm{C}$, acompanhada de um pico endotérmico na curva de análise térmica diferencial (ATD), o que corresponde à temperatura de desidroxilação da caulinita, na qual o íon $\mathrm{OH}$ - estrutural é liberado na transformação da caulinita em metacaulinita [19-21]. Também nessa faixa de temperatura a presença de quartzo pode ser detectada a $573{ }^{\circ} \mathrm{C}$, com a transformação $\alpha \rightarrow \beta$ [22], com um leve pico exotérmico na curva de ATD. Em aproximadamente $980^{\circ} \mathrm{C}$, o pico exotérmico correspondente a formação de mulita $\left(3 \mathrm{Al}_{2} \mathrm{O}_{3} \cdot 2 \mathrm{SiO}_{2}\right)[23-25]$.

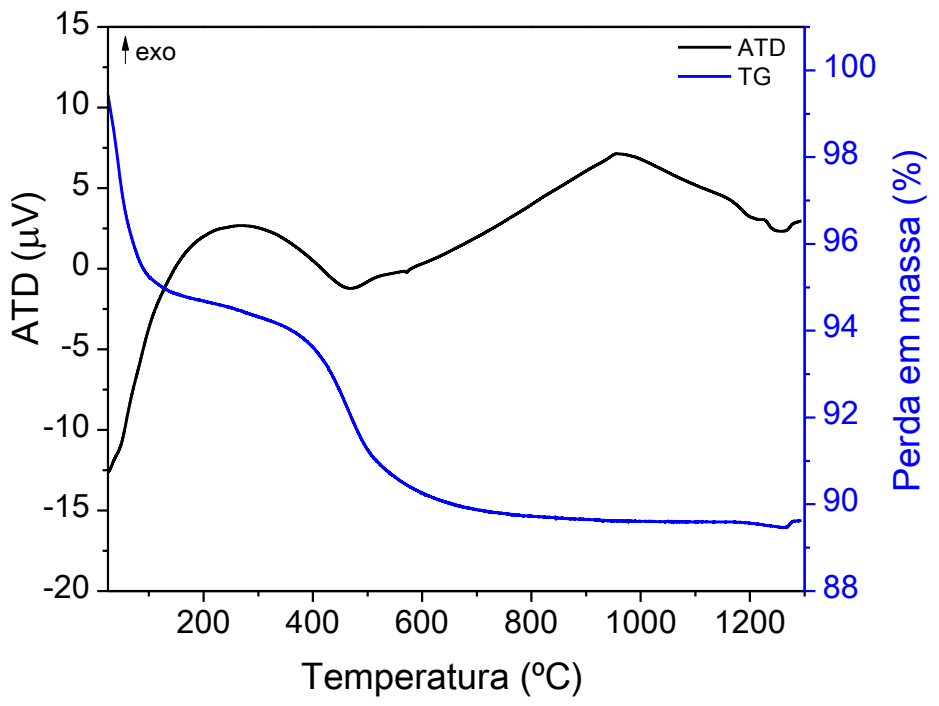

Figura 2: Análise térmica diferencial e termogravimétrica da argila.

Pela análise da Figura 3, pode-se observar que o processo de retração/densificação da argila tem início em aproximadamente $800^{\circ} \mathrm{C}$. Entre 800 e $1100^{\circ} \mathrm{C}$ é possível observar uma retração atribuída a formação de contatos e aproximação entre as partículas. No entanto, a partir de $1100{ }^{\circ} \mathrm{C}$ observa-se forte retração (queda acentuada da curva dilatométrica) relacionada ao desenvolvimento de fase líquida viscosa promovida pelos fundentes presentes na argila que promovem a densificação do material [17,26]. Com base nos resultados das análises térmicas foi possível determinar o ciclo de queima das amostras. Para que as reações de perda em massa e transformação de fases possam ocorrer sem causar danos a estrutura do material, a taxa de aquecimento que pode ser utilizada é de $7^{\circ} \mathrm{C} / \mathrm{min}$. Além disso, observa-se que para obter materiais cerâmicos densos é necessário queimá-los em temperaturas acima de $900^{\circ} \mathrm{C}$. Por esse motivo as temperaturas de queima selecionadas foram 950 e $1100^{\circ} \mathrm{C}$.

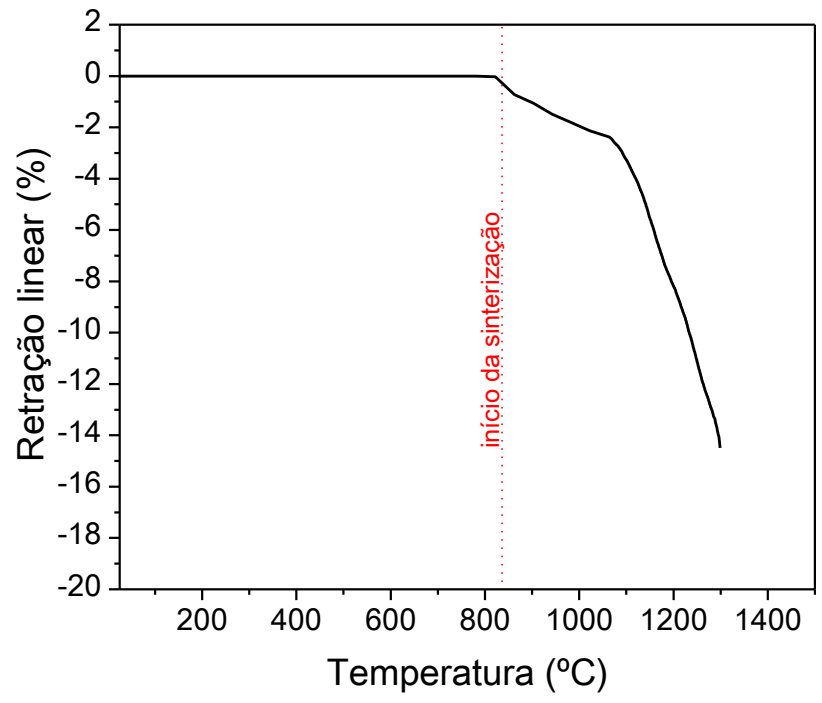

Figura 3: Retração linear da matriz cerâmica. 
A densidade das amostras antes da queima (densidade a verde) é apresentada na Tabela 3. Pode-se observar que o glicerol provoca um aumento de aproximadamente 5,5\% na densidade a verde das amostras. Este aumento está relacionado a um melhor empacotamento das amostras durante o processo de prensagem e provavelmente ocasionará uma melhora em demais propriedades do material.

Tabela 3: Densidade a verde das amostras.

\begin{tabular}{cc}
\hline AMOSTRAS & DENSIDADE A VERDE $\left(\mathbf{g} / \mathbf{c m}^{\mathbf{3}}\right)$ \\
$100 \%$ Argila & $1,90 \pm 0,3$ \\
$10 \%$ Glicerol & $2,01 \pm 0,2$ \\
\hline
\end{tabular}

Os resultados de absorção de água, porosidade aparente, retração linear de queima e densidade aparente das amostras, são apresentados na Tabela 4.

Tabela 4: Absorção de água, porosidade aparente, retração linear e densidade das amostras.

\begin{tabular}{ccccc}
\hline AMOSTRA & AA (\%) & PA (\%) & RLQ (\%) & \rangle$_{\text {AP }}\left(\mathbf{g} / \mathbf{c m}^{3}\right)$ \\
$100 A 950$ & $15,24 \pm 0,69$ & $27,31 \pm 1,06$ & $0,88 \pm 0,38$ & $1,77 \pm 0,05$ \\
10G950 & $14,96 \pm 0,26$ & $26,09 \pm 0,36$ & $1,02 \pm 0,35$ & $1,77 \pm 0,05$ \\
100 A1100 & $10,98 \pm 0,44$ & $21,12 \pm 0,48$ & $3,58 \pm 0,18$ & $1,90 \pm 0,03$ \\
$10 G 1100$ & $10,69 \pm 0,67$ & $21,41 \pm 1,48$ & $3,79 \pm 0,22$ & $1,87 \pm 0,03$ \\
\hline
\end{tabular}

É possível observar, com relação à absorção de água, que as amostras queimadas na temperatura de $950{ }^{\circ} \mathrm{C}$ possuem uma maior absorção com relação as amostras queimadas na temperatura de $1100{ }^{\circ} \mathrm{C}$. Este fato pode ser explicado pela porosidade do material, característico da queima a esta temperatura. Aumentando-se a temperatura de queima para $1100{ }^{\circ} \mathrm{C}$, percebe-se uma redução na absorção de água, o que é esperado, já que ocorre o desenvolvimento de fase líquida viscosa promovida pelos fundentes presentes na argila nestas condições, o que deixa o material mais denso, ou seja, menos poroso [15, 18, 27-30]. Para as duas temperaturas de queima foram observados aumentos da absorção de água com a adição do glicerol. Observa-se também, pela análise da Tabela 3, que ocorre um aumento na retração linear com o aumento da temperatura de queima de $950^{\circ} \mathrm{C}$ para $1100^{\circ} \mathrm{C}$. A quantidade de água absorvida é proporcional à quantidade de poros abertos que há no material, sendo que em sinterizações apropriadas, espera-se uma quantidade mínima de poros abertos. [31] Observa-se que com a utilização do glicerol, ocorre um pequeno aumento nos valores de retração, o que já era esperado, já que o glicerol é degradado durante o processo de queima, restando apenas à matriz cerâmica. Os valores de retração mais baixos foram obtidos para as amostras sinterizadas a temperaturas mais baixas, $950{ }^{\circ} \mathrm{C}$ [32]. Além disso, pode-se observar que os valores obtidos para a densidade aparente após a queima para as amostras com e sem a agregação do glicerol são bem similares, o que demonstra que o glicerol não afeta na densidade aparente material final. Ainda com relação à agregação do glicerol, o mesmo não provocou alterações significativas para a absorção, porosidade e retração do material, fato importante, pois sua agregação à argila manteve as propriedades físicas da mesma, diminuindo a quantidade de argila a ser utilizada no processo ao mesmo tempo em que agrega valor a possibilidade de utilização do glicerol residual da produção do biodiesel.

Segundo as normas da Associação Brasileira de Normas Técnicas (ABNT), apresentadas na Tabela 5, os resultados de absorção de água servem como parâmetro para sua classificação do material e utilização como telhas ABNT NBR 15310:2009 [33], blocos cerâmicos ABNT NBR 15270-3:2005 [34] e placas cerâmicas de revestimento ABNT NBR 13818:1997 [35]. 
Tabela 5: Classificação dos materiais cerâmicos quanto à absorção de água de acordo com as NBR's.

MATERIAIS CERÂMICOS

TELHAS

ABNT NBR 15310:2009

BLOCOS CERÂMICOS

ABNT NBR 15270-3:2005

PLACAS DE REVESTIMENTO

ABNT NBR 13818:1997

\section{ABSORÇÃO DE ÁGUA}

Valores menores ou iguais a $18 \%$.

Valores entre 8 e $18 \%$.

Pode variar ente 0,5 e $10 \%$ ou superior a este, dependendo do material.

De acordo com essa classificação, as amostras constituídas de argila e glicerol queimados a $1100{ }^{\circ} \mathrm{C}$ se enquadrariam tanto para a fabricação de telhas quanto para blocos cerâmicos.

A Figura 4 apresenta as micrografias das amostras 100A950 (a), 10G950 (b), 100A1100 (c) e $10 \mathrm{G} 1100(\mathrm{~d})$.
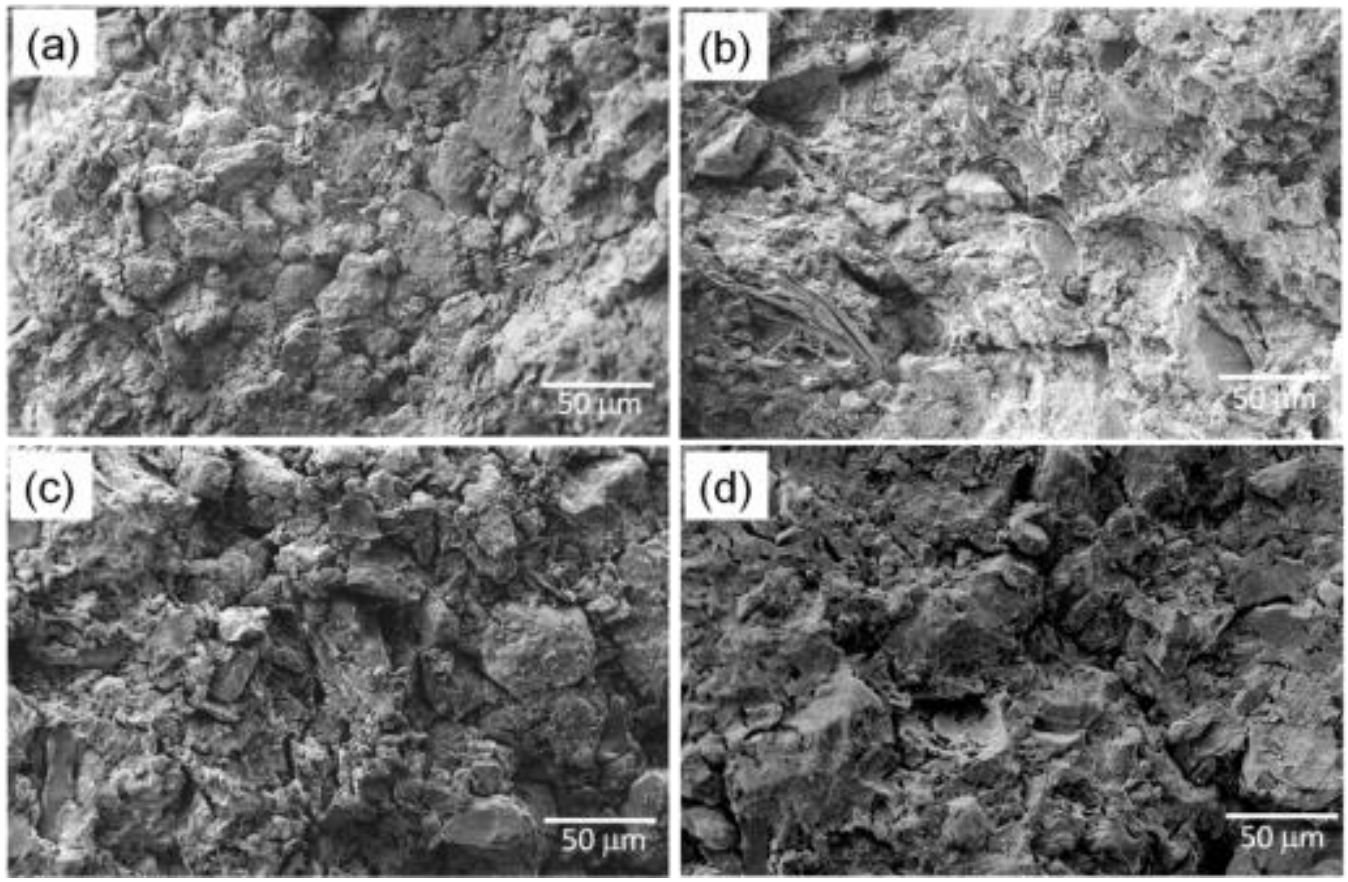

Figura 4: Micrografias das amostras 100A950 (a), 10G950 (b), 100A1100 (c) e 10G1100 (d).

Pode-se observar, pela análise da Figura 4, que as amostras são bem semelhantes. A adição de glicerol não ocasionou diferenças microestruturais significativas que possam estar relacionadas a um aumento da porosidade, por exemplo. Sua agregação à argila manteve as propriedades da mesma, diminuindo a quantidade de argila a ser utilizada no processo. Além disso, é possível observar que as amostras queimadas a $1100^{\circ} \mathrm{C}(\mathrm{c}$, d) possuem uma melhor homogeneidade microestrutural se comparadas com as amostras queimadas a $950{ }^{\circ} \mathrm{C}$ (a,b). Essa melhor homogeneidade microestrutural pode refletir em uma melhoria nas propriedades mecânicas.

A Figura 5 apresenta os dados de resistência mecânica para as diferentes temperaturas de queima das amostras contendo $100 \%$ de argila e com a adição de $10 \%$ de glicerol. 


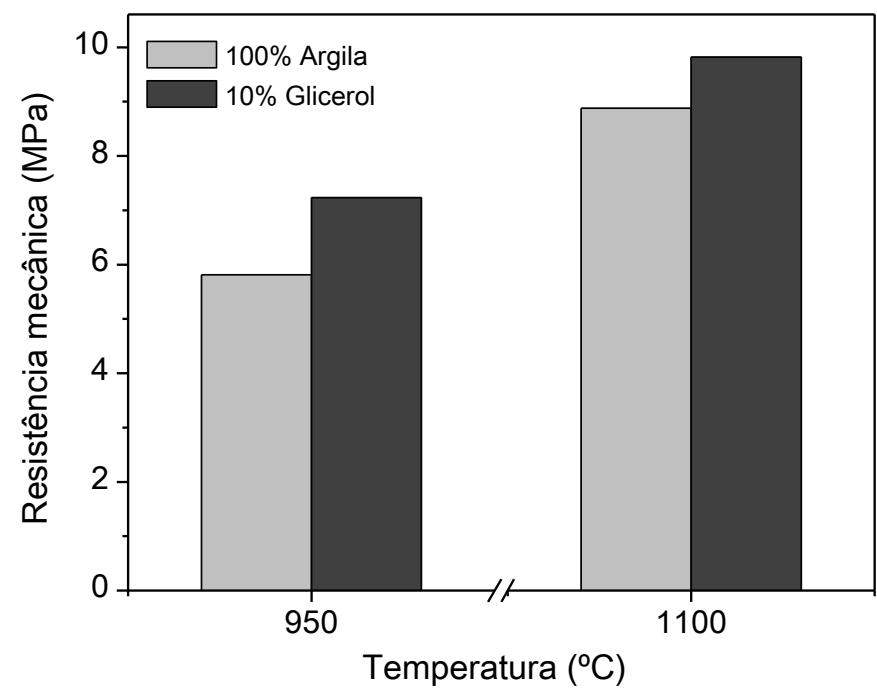

Figura 5: Resultados de resistência mecânica para as diferentes temperaturas de queima.

Pode-se observar um aumento da resistência à flexão com o aumento da temperatura de queima, uma vez que há uma diminuição da porosidade quando se aumenta a temperatura, caracterizando o início da fase vítrea [36-41]. Vale salientar que a adição do glicerol aumenta a resistência mecânica das amostras, para as duas temperaturas de queima.

A Tabela 6 apresenta a classificação quanto à resistência mecânica, de acordo com a ABNT, para telhas ABNT NBR 15310:2009 [33], blocos cerâmicos ABNT NBR 15270-3:2005 [34] e placas cerâmicas de revestimento ABNT NBR 13818:1997][35]. Os valores de resistência mecânica são muito variáveis devido aos diferentes materiais que podem compor a massa cerâmica.

Tabela 6: Classificação dos materiais cerâmicos quanto à resistência mecânica de acordo com as NBR's.

MATERIAIS CERÂMICOS

Telhas

ABNT NBR 15270-3:2005

Blocos cerâmicos

ABNT NBR 13818:1997

Placas de revestimento

ABNT NBR 13818:1997

\section{RESISTÊNCIA MECÂNICA}

Os valores podem variar entre 6,8 a 9,8, sendo no máximo $12,7 \mathrm{MPa}$.

Está dividido em classes, sendo o valor mínimo $1 \mathrm{MPa}$.

Pode variar entre 15 e $35 \mathrm{MPa}$, podendo ainda ser superior.

De acordo com a classificação, todas as amostras seguem os parâmetros para telhas e blocos cerâmicos, exceto a amostra 100AR950 (100\% de argila, queimada a $\left.950{ }^{\circ} \mathrm{C}\right)$. Portanto, as amostras contendo glicerol agregado, parecem promissoras do ponto de vista de resistência mecânica, tendo sido observada a diminuição do uso de argila e a agregação de resíduo como forma de valoração do mesmo, o que não afetou a função do material cerâmico.

\section{CONCLUSÕES}

A adição do glicerol a argila para obtenção de um material cerâmico apresentou resultados satisfatórios. Com a adição do glicerol, não houve alterações significativas para absorção de água e porosidade aparente do material cerâmico. Sua agregação à argila manteve as propriedades físicas da mesma, diminuindo a quantidade de argila a ser utilizada no processo ao mesmo tempo em que agrega valor ao resíduo da produção do biodiesel. Melhorias quanto à resistência mecânica foram comprovadas e, mesmo não havendo alterações significativas quanto à absorção de água, o estudo da adição de alguns aditivos poderia melhorar esta característica, buscando um material com as propriedades necessárias para aceitação no mercado. Ainda, a utilização do glicerol reduz o gasto com matérias-primas naturais, como a argila. Apesar de a quantidade agregada não ser grande, quando se pensa em escala industrial os resultados obtidos neste trabalho podem levar a diferenças que podem ser bastante significativas. 


\section{AGRADECIMENTOS}

Os autores agradecem à CAPES, CNPq, e ao LACER-UFRGS por disponibilizar espaço e equipamentos que auxiliaram na realização desta pesquisa.

\section{BIBLIOGRAFIA}

[1] AGÊNCIA NACIONAL DO PETRÓLEO, Produção de Biodiesel. Brasil, 2016. Acesso em: 07/12/2016.

[2] MOTA, C.J.A., SILVA, C.X.A.D., GONÇALVES, V.L.C. "Gliceroquímica: novos produtos e processos a partir da glicerina de produção de biodiesel”, Química Nova, v. 32, pp. 639-648, 2009.

[3] GAMA, P.E., GIL, R.A.D.S.S., LACHTER, E.R. "Produção de biodiesel através de transesterificação in situ de sementes de girassol via catálise homogênea e heterogênea", Química Nova, v. 33, pp. 1859-1862, 2010.

[4] BEATRIZ, A., ARAÚJO, Y.J.K., LIMA, D.P.D. "Glicerol: um breve histórico e aplicação em sínteses estereosseletivas”, Química Nova, v. 34, pp. 306-319, 2011.

[5] TAN, H.W., ABDUL AZIZ, A.R., AROUA, M.K. "Glycerol production and its applications as a raw material: A review", Renewable and Sustainable Energy Reviews, v. 27, pp. 118-127, 2013.

[6] GOMES, M.C.S., PEREIRA, N.C., BARROS, S.T.D.D. "Separation of biodiesel and glycerol using ceramic membranes", Journal of Membrane Science, v. 352, n. 1-2, pp. 271-276, 2010.

[7] CASAGRANDE, M.C., SARTOR, M.N., GOMES, V., et al., "Reaproveitamento de resíduos sólidos industriais: processamento e aplicações no setor cerâmico", Cerâmica Industrial, v. 13, n. 1/2, pp. 34-42, 2008.

[8] MORINI, A.A., OLIVEIRA, K.A.D., PEREIRA, F.R., et al., "Avaliação da Potencialidade do Uso de Resíduos Industriais através de Ferramenta de Seleção de Materiais para Projeto de Produtos Cerâmicos", Cerâmica Industrial, v. 21, n. 2, pp.36-44, 2016.

[9] MARTÍNEZ-GARCÍA, C., ELICHE-QUESADA, D., PÉREZ-VILLAREJO, L, et al., "Sludge valorization from wastewater treatment plant to its application on the ceramic industry", Journal of environmental management, v. 95, pp. S343-S348, 2012.

[10] GODINHO, K.O., HOLANDA, J.N.F., SILVA, A.G.P. "Efeito da adição de vidro sobre propriedades de queima de uma argila vermelha", In: Anais do $49^{\circ}$ Congresso Brasileiro de Cerâmica, CBC, São Pedro-SP, CD-ROM, 2005.

[11] SOUZA NANDI, V., ZACCARON, A., FERNANDES, P., et al., "Adição de Vidro Reciclado de Lâmpadas na Fabricação de Cerâmica Vermelha”, Cerâmica Industrial, v.19, n.5, pp.29-32, 2014.

[12] RAUT, S.P., RALEGAONKAR, R.V., MANDAVGANE, S.A. "Development of sustainable construction material using industrial and agricultural solid waste: A review of waste-create bricks", Construction and Building Materials, v. 25, n. 10, pp. 4037-4042, 2011.

[13] ELICHE-QUESADA, D., MARTÍNEZ-MARTÍNEZ, S., PÉREZ-VILLAREJO, L., et al., "Valorization of biodiesel production residues in making porous clay brick", Fuel Processing Technology, v. 103, pp. 166173, 2012.

[14] AMERICAN SOCIETY FOR TESTING AND MATERIALS. Test method for crushing strenght and modulus of rupture of refractories. ASTM C 133/97. Philadelphia 1995.

[15] CARGNIN, M., SOUZA, S.D., DE SOUZA, A., et al., "Determination of kinetic parameters of sintering of ceramic type BIIa single firing", Cerâmica, v. 57, n. 344, pp. 461-466, 2011.

[16] LOPEZ, S.Y.R., YOBANNY, S., RODRIGUEZ, J.S., et al., "Determination of the activation energy for densification of porcelain stoneware", Journal of Ceramic Processing Research, v. 12, n. 3, pp. 228-232, 2011.

[17] SANTOS, C., OLIVEIRA, H., OLIVEIRA, R., et al., "Characterization of calcareous clay used in the production of ceramic tiles in Sergipe State-Brazil", Cerâmica, v. 62, n. 362, pp. 147-156, 2016.

[18] SOUSA, S. Ciência e tecnologia de argilas. Edgard Blucher Ltda, São Paulo-SP, v1, 1989.

[19] BELLOTTO, M., GUALTIERI, A., ARTIOLI, G., et al., "Kinetic study of the kaolinite-mullite reaction sequence. Part I: kaolinite dehydroxylation”, Physics and Chemistry of Minerals, v. 22, n. 4, pp. 207-217, 1995. 
[20] ZEMENOVÁ, P., KLOUŽKOVÁ, A., KOHOUTKOVÁ, M., et al., "Investigation of the first and second dehydroxylation of kaolinite", Journal of Thermal Analysis and Calorimetry, v. 116, n. 2, pp. 633-639, 2014.

[21] WALKER, G.F., COLE, W.F., MACKENZIE, R.C. The differential thermal investigation of clays. Mineralogical Society, London, p. 191, 1957.

[22] BENTAYEB, A., AMOURIC, M., OLIVES, J., et al., "XRD and HRTEM characterization of pyrophyllite from Morocco and its possible applications", Applied clay science, v. 22, n. 5, pp. 211-221, 2003.

[23] HAJJAJI, M., KACIM, S., ALAMI, A., et al., "Chemical and mineralogical characterization of a clay taken from the Moroccan Meseta and a study of the interaction between its fine fraction and methylene blue", Applied Clay Science, v. 20, n. 1, p. 1-12, 2001.

[24] ACCHAR, W. Materiais cerâmicos: caracterização e aplicações. Natal-RN, Ed. UFRN, 2006.

[25] PEŠOVÁ, A., ANDERTOVA, J., GEDEON, O. "Hydrothermal Degradation of Ceramic Materials on the Natural Raw Materials Base. Part 2: Structural changes", Ceramics-Silikáty, v. 54, n. 2, pp. 176-181, 2010.

[26] ROSA, F., FOLGUERAS, M., LONGO, A., et al., "Caracterização de resíduos industriais para uso na composição de massas cerâmicas”, Tile and Brick International, v. 18, n. 1, pp. 20-23, 2002.

[27] MOREIRA, J.M.S., FREIRE, M.N., HOLANDA, J.N.F. "Utilização de resíduo de serragem de granito proveniente do estado do Espírito Santo em cerâmica vermelha", Cerâmica, v. 49, pp. 262-267, 2003.

[28] FREITAS, L.A.D., MONTEIRO, S.N., SÁNCHEZ, R., et al., "Incorporação de coque de petróleo em cerâmica vermelha", Cerâmica, v. 57, pp. 206-211, 2011.

[29] ANDRADE, P.M., NETO, H.S.N., MONTEIRO, S.N., et al., "Efeito da adição de fonolito na sinterização de argila caulinítica", Cerâmica, v. 51, pp. 362-371, 2005.

[30] SÁNCHEZ-MUÑOZ, L., CAVA, S.D.S., PASKOCIMAS, C.A., et al., "Seleção de matérias-primas no desenvolvimento de formulações de massas cerâmicas", Cerâmica, v. 48, pp. 108-113, 2002.

[31] OLIVEIRA, G.E., HOLANDA, J.N.F. "Reaproveitamento de resíduo sólido proveniente do setor siderúrgico em cerâmica vermelha”, Cerâmica, v. 50, pp. 75-80, 2004.

[32] DINGER, D.R. "Utilização das sub-rotinas DRD para ajustar a retração de queima e a absorção de água de produtos extrudados", Cerâmica Industrial, v. 9, n. 3, pp. 24-29, 2004.

[33] ASSOCIAÇÃO BRASILEIRA DE NORMAS TÉCNICAS. Componentes cerâmicos - Telhas - Terminologia, requisitos e métodos de ensaio. ABNT NBR 15310. Brasil 2009.

[34] ASSOCIAÇÃO BRASILEIRA DE NORMAS TÉCNICAS Componentes cerâmicos. Parte 3: Blocos cerâmicos para alvenaria estrutural e de vedação - Métodos de ensaio. ABNT NBR 15270-3. Brasil 2005.

[35] ASSOCIAÇÃO BRASILEIRA DE NORMAS TÉCNICAS. Placas cerâmicas para revestimento - Especificação e métodos de ensaios. ABNT NBR 13818. Brasil 1997.

[36] MOREIRA, J.M.S., MANHÃES, J.P.V.T., HOLANDA, J.N.F. "Reaproveitamento de resíduo de rocha ornamental proveniente do Noroeste Fluminense em cerâmica vermelha", Cerâmica, v. 51, pp. 180-186, 2005.

[37] VIEIRA, C.M.F., SOARES, T.M., MONTEIRO, S.N. "Massas cerâmicas para telhas: características e comportamento de queima", Cerâmica, v. 49, pp. 245-250, 2003.

[38] VIEIRA, C.M.F., SALES, H.F., MONTEIRO, S.N. "Efeito da adição de argila fundente ilítica em cerâmica vermelha de argilas cauliníticas”, Cerâmica, v. 50, pp. 239-246, 2004.

[39] SOUZA, G.P., HOLANDA, J.N.F. "Comportamento de sinterização de massas argilosas contendo resíduo proveniente do setor petrolífero", Cerâmica, v. 49, pp. 128-132, 2003.

[40] TELOEKEN, A.C., VILLANOVA, D.L., BASEGIO, T.M., et al., "Utilização de lodo galvânico como matéria--prima em cerâmica vermelha e caracterização dos corpos cerâmicos obtidos quanto a propriedades tecnológicas e a imobilização de metais", Cerâmica Industrial, v. 16, n. 2, pp. 14-19, 2011.

[41] SILVA, J.B., HOTZA, D., SEGADÃES, A.M., et al., "Incorporação de lama de mármore e granito em massas argilosas (Incorporation of marble and granite sludge in clay materials)", Cerâmica, v. 51, pp. 325$330,2005$. 


\section{ORCID}

Adriane Lawisch Rodríguez

Pâmela Andréa Mantey dos Santos

Adilson Becker Jr

Diosnel Antonio Rodriguez Lopez

Ênio Leandro Machado

Tiago Bender Wermuth

Sabrina Arcaro https://orcid.org/0000-0003-2923-6677

https://orcid.org/0000-0003-1302-9454

https://orcid.org/0000-0002-0213-7030

https://orcid.org/0000-0002-4620-715X

https://orcid.org/0000-0003-0140-4966

https://orcid.org/0000-0003-0120-3478

https://orcid.org/0000-0002-0668-7689 